Research Article

\section{Postgraduate students' perception of the educational environment of a wet lab training in Neurological Surgery Division, UCH, Ibadan}

\author{
Malomo Adefolarin $0^{1 *}$, Kafayat Bolaji Aminu², Adeolu Augustine \\ $\mathbf{A}^{1}$, Adeleye Amos $0^{1}$, Balogun James Aㄹ, Badejo Oluwakemi A $^{1}$, \\ Shokunbi Mathew $\mathrm{T}^{1}$ and Jegede Ayodele $\mathrm{S}^{2}$
}

${ }^{1}$ Department of Neurological Surgery, University College Hospital, Ibadan and Department of Surgery, College of Medicine, University of Ibadan, Ibadan, Nigeria

${ }^{2}$ Department of Sociology, Faculty of the Social Sciences, University of Ibadan, Ibadan, Nigeria

\section{Summary}

Objective: The importance of understanding the perceptions of medical students to their training environment cannot be overemphasized. The study evaluated the wet lab training organized for Senior Registrars in the Neurosurgery, Division of the University College Hospital, Ibadan.

Aim: The purpose of this study is to assess the experiences of postgraduate students during wet-lab training with the aim of improving the course content and introducing evidence-based and student-centered changes.

Methodology: The study made use of a cross-sectional design and data were collected using the qualitative research approach. Information was elicited from all the Senior Registrars who participated in the training through in-depth interviews.

Result: All the postgraduate students who participated in the training were satisfied with the course content and the method of delivery appropriated during the training. They also found it relevant to their practice. However, certain shortcomings were observed such as high cost of training, poor standard of equipment/tools, tight work schedule and short training duration.

Conclusion: Hands-on training plays an important role in enhancing the quality of care and high performance in health-care service delivery. The shortcomings and suggestions for improving future trainings as reported by the residents should be addressed in order to maximize the gains of the hands-on training experience.

\section{More Information}

*Address for Correspondence: Malomo Adefolarin O, Department of Neurological Surgery, College of Medicine, University College Hospital, Ibadan, Nigeria, Tel: +2348034852526, +2347031193289:

Email: ademalomo@yahoo.com;

bolkaf@yahoo.com; aminukafayat@gmail.com

Submitted: 11 November 2019

Approved: 11 December 2019

Published: 12 December 2019

How to cite this article: Malomo Adefolarin 0 , Aminu KB, Adeolu Augustine A, Adeleye Amos O, Balogun James A, et al. Postgraduate students' perception of the educational environment of a wet lab training in Neurological Surgery Division, UCH, Ibadan. Clin J Nurs Care Pract. 2019; 3 : 064-069.

DOI: dx.doi.org/10.29328/journal.cjncp. 1001020 Copyright: Malomo Adefolarin 0 , et al. This is an open access article distributed under the Creative Commons Attribution License, which permits unrestricted use, distribution, and reproduction in any medium, provided the original work is properly cited.

Keywords: Wet lab training; Neurosurgery; University College Hospital; Medical education; Training environment

D) Check for updates

\section{Introduction}

The perception of students determine their attitude, academic progress and practice as professionals, to a large extent. Therefore, understanding the opinions of students/trainees is of utmost importance when evaluating the environment of medical education [1]. The quality of an educational program, as well as, the evaluation of their training, can be improved and modified through the feedback of students [2]. Investigations on students' views of their learning environments have focused mostly on other educational disciplines like Architecture, Education and Communication while attention is just lately shifting to students of the clinical health sciences.
Scholars describe the educational or learning environment to mean all the happenings within the classroom; the faculty or department, as well as, the institution as a whole [2,3]. In this context, all activities and interactions, relating to academic pursuits, taking place within an institution constitute the educational or learning environment. In the clinical sciences, researchers adopt different approaches to assess the medical educational environment. The most widely used standardized instrument in such settings is the Dundee Ready Educational Environment Measure (DREEM) questionnaire by the Delphi panel. This has been applied among undergraduate medical students across locations like Nigeria; Nepal and Saudi Arabia [4-6], especially amongst Physiotherapy clinical students [7]. The wet lab is an emerging, important aspect of 
undergraduate and postgraduate medical training in surgical specialties because it is an effective technique for acquiring both theoretical knowledge and hands-on skills for medical students [8]. Along with surgical videos, the wet-lab is a handy approach for trainee surgeons to safely simulate practice on patients [9]. As an important aspect of the education of medical students, the aim of the wet lab course is to provide hands-on surgical training focused on developing surgical skills, experience, competence and confidence amongst medical students for the purpose of improving treatment outcomes and reducing complications. However, due to the high costs of setting up a well-equipped wet lab in medical schools, especially, in resource-constrained countries, trainee surgeons rarely have access to simulation training. Due to this, many residents have to rely on sessions in the operating theatre and surgical videos for learning.

To address this training gap in our center, recently, a wet lab training was organized for the trainee neurosurgeons in the Neurological Surgery Division of the University College Hospital (UCH), Ibadan. It was the first of such courses in the Unit for postgraduate medical students. As part of the evaluation, an assessment of the training was conducted and the results of the evaluation are documented in this study with the aim of improving the quality and viability of the course content. Through the feedbacks gotten during this research, it is hoped that necessary modifications would be made in order to serve the trainees better and to improve the wet lab training to a standard that can meet the world trends in medical practice.

\section{Materials and Methods}

\section{Study design and setting}

The study is cross-sectional and qualitative by design. The setting is the University College Hospital (UCH), Ibadan.

\section{Participants}

All the postgraduate medical students undergoing resident training in the Neurosurgery Division of UCH were sampled. Therefore, this was a 'total population' study. In essence, no sampling approach was used in selecting the research participants. In all, eight (8) senior registrars (all male) took part in the wet lab training and were surveyed for this study. In total, eight resident doctors consented to be part of the study.

\section{Data collection procedure}

Individual interviews were conducted with all eight of the eligible Senior Registrars who participated in the said wet lab training, a couple of weeks following the training. The instrument used in this study was a semi-structured in-depth interview guide developed with questions adapted from the DREEM questionnaire. The instrument comprises questions on different subscales of the DREEM questionnaire (students' perception of learning, students' perception of teachers, students' perception of atmosphere and students' academic self-perception). Different domains of the educational environment such as the quality of the teacher(s), facilities and the atmosphere were equally assessed. The qualitative approach was used for the evaluation because it is an essential and major factor in training assessment. By definition, the qualitative method basically refers to subjective experience and appraisal. It remains an important aspect of overall product evaluation as it brings out subjective interpretation of human experiences which cannot be captured using the quantitative approach. Subjective interpretations determine the patronage and sustenance of any entity or product. The neglect of subjective interpretations in the evaluation of products could be viewed as a form of inadvertent hubris which usually impairs the utility of qualitative values of products. In our environment, especially amongst physicians, purely qualitative evaluation of output is quite uncommon compared to its alternatives. The purpose of this study, therefore, is to undertake the assessment of a well-planned and carefully executed activity among Neurosurgery Senior Registrars.

\section{Data analysis}

The analysis was done with the aid of ATLAS.ti (v. 7) software. The software was utilized for coding relevant themes identified after transcribing the data. Identified codes were assigned to different code families, frequencies of similar responses were taken and the appropriate quotes that best capture the theme were selected from the transcripts. The results were presented under common themes using verbatim quotations where necessary and contents analyzed for easy understanding.

\section{Ethical consideration}

The study was approved by the Head of the Neurosurgery Division of the hospital. In addition, no identifying information was obtained or used in the study. All the participants consented to be part of the research after the procedure and purpose of the investigation have been discussed with each and every one of them. Ethical principles were strictly adhered to and the study constituted no harm to the study group.

\section{Results}

A total of eight in-depth interviews were conducted with the trainee Neurosurgeons who participated in the wet lab training experience. All the participants were male and undergoing postgraduate training. The results of the interviews are presented in this section and grouped under sub-sections for better understanding.

\section{Perception of the training}

All the participants rated the wet-lab training as very good 
and satisfactory. They found it useful to their postgraduate education and career development. Different phrases were used to describe the training.

The major themes include:

- Very necessary for the training of the residents

- An integral part of comprehensive grooming of wouldbe Neurosurgeons

- A welcome development

- An eye-opener

- A form of active learning

- Educative and enriching

The quote below represents the perception of the trainees about the wet lab training:

I think it is wonderful. It should be incorporated into the program...it fortified what we knew from different consultants, the same approach so there was uniformity without fear. So every other thing was okay, hands-on, oneon-one with your tutor...it was quite efficient (IDI: 3/ Male/ SR).

In the above excerpt, the participant highlights aspects of the training he found most relevant such as the lack of fear in carrying out surgical procedures and the opportunity to interact with tutors closely while seeking clarifications which further emboldened the trainees. This was possible because the laboratory environment was different from the operating theatre where the patient is put under anesthesia and time is of the essence.

\section{Benefits of the training}

Furthermore, the participants were asked to describe the benefits derived from the laboratory session. They all agreed that it was beneficial, some of the themes from their responses are summarised below:

- Helped to build confidence/reduced fear

- Increased hope in medical training

- $\quad$ Prepared trainees for real-life situations

- Fortified theoretical knowledge

- Increased understanding of some concepts

- Provided opportunity to learn closely

\section{Expectations met through the training}

All the participants except one reported that the training surpassed their expectations. The dissenting voice explained that he had mastered most of the procedures before the training and as such his expectations were not surpassed:
...These are things I had been doing...it was just like a routine that we must fulfill...for someone who is just starting training, it would be a great thing but for someone who has gone beyond that level...it was like a retro... (IDI: 8/ Male/ $\mathrm{SR})$.

The interviewee revealed that he had been learning some of the procedures on his own before the training and had mastered them, explaining his perception. However, for others who did not have such an opportunity, it met their expectations and even surpassed it. One of such participants expresses it thus:

I wasn't really expecting much, I just felt like it's going to be like the normal skills course...but it was a lot more than that...it was quite advanced, we went further to very specific things pertaining to Neurological Surgery. It wasn't general this time, it was very specific and we did quite a lot (IDI: 4/ Male/ SR).

Although the students had participated in other training, they believed the laboratory training in question was better and advanced with respect to content. They were satisfied because they had expectations with regard to things they were hoping to gain from the training. The training, according to them, covered every aspect, including some uncommon surgical techniques that were not seen frequently in the theatre due to the peculiarity of such cases. They indicated that they were put through the rudiments of the rare surgical procedures by the trainers. Apart from learning the rare procedures, the trainees also got to understand different techniques of carrying out certain surgical procedures and how to ensure a better patient outcome.

\section{The usefulness of the training to practice}

The participants believed the training would be useful to their careers and future practices because it helped them build confidence in their ability to carry out certain surgical procedures. Their confidence level had been increased through the training. According to a participant:

...It built confidence..., it also helped to expand our hope... Practically, everyone gained one thing or the other. I particularly gained a lot maybe because I am still very young in the training but I gained a lot...it's what we need to do in the course of this training. (IDI: 5/ Male/ SR)

In addition, practicing on brain models was expected to eliminate the likelihood of committing significant errors on the live human brain which is very delicate and where mistakes may be at great costs to the life or well-being of the patients. The skills needed to practice safely were acquired during the training. Hence, the training was perceived as relevant to future practices of the trainees as Neurosurgeons. 


\section{Worth time and resources}

All participants interviewed except one reported that the training was worthy of their time and resources. They found it time-worthy because it touched on critical aspects of their training. According to most of the Residents, it helped them to understand a lot of things which they only had the opportunity of observing in the operating theatre. The laboratory session, however, enabled the trainees to understand the very basis of different procedures and how they could be performed. One participant stated such by stating that:

...It was an opportunity for you to be there and learn from people showing you step-by-step what should be done...you are even allowed to practice in a safe way and then you can improve your skills over time. (IDI: 6/ Male/ SR).

\section{Problems identified}

Despite the fact that the residents perceived the wet lab training as relevant and important to their career development, they, however, identified problems and issues which emerged in the course of the training.

Some of which included:

- The high cost of training

- Poor standard equipment/tools

- Tight work schedule

- Training not exhaustive

- Short training duration

- Substandard specimen

- Challenges with logistic

These challenges emerged probably because the laboratory session was the first of its kind in the Unit and so it was not without some "teething problems". The statements presented next capture somewhat more graphically some of the problems identified above:

The problems are what we expected because there was not much time, every program was packed within a day so it wasn't exhaustive even though detailed but not exhaustive. Two, not having some appropriate instruments and moreover what we were dealing with was not a human being. It can only look like a human being...the anatomy of the goat is different or ram is different from that of the human we tend to tear some layers...we missed some, we skipped some because it's not the same platform...so every other thing was okay... (IDI: 3/ Male/ SR).

The participant reported that because the training was done on a single day, it was difficult to exhaust everything possible within the course content. It was equally noted that some of the instruments used for the training were locally made and were not as precise as the instruments used in the operating theatre. Furthermore, the residents had to deal with their normal duty during the laboratory training which they found stressful. Another problem observed was that not all the participants had access to human brain specimens as they were inadequate. As a result, the trainees had to use animal brain specimen which is not a full representation of human brain anatomy. The risks in using animal brain specimens include possible transmission of zoonotic diseases. However, contrary to the opinion of others, a dissenting voice did not identify any problem with the training:

I don't think there are issues...considering the fact that we had an excess of everything (IDI: 4/ Male/ SR).

\section{Suggestions for improvement}

Being the end-users of the training and given the problems identified, the participants suggested ways of addressing the challenges and maximizing the opportunities of the continuation of such in the near future.

These suggestions are grouped as follows:

- Extend the training time and training sessions

- Adequate preparation ahead of time

- Source for funds

- Invite other stakeholders

- Extend training to other institutions within and outside Nigeria

- Improve on the logistics

The residents advised that adequate preparation be made before the next training while more people should be involved in the process. They also wanted participation in the training to be extended to trainees in other medical centers. In addition, it was suggested that the training be made a requirement for undergraduate medical students.

\section{Discussion}

The role of students in improving the quality of their learning environment cannot be overemphasized and for them to effectively play that part, they must be involved in the evaluation of their training. In this wise, students must be seen as collaborators and not passive receivers in their medical socialization [10]. Several studies have assessed the students' perception of their learning environment. Most of them found a positive outcome. The finding of this evaluation also supports this positive trend. The study revealed that the education environment of the wet lab training was favorably rated by the resident neurosurgeons. This is similar to the result of a study by Sideris, et al. [8] among undergraduate Greek and UK students who participated in a wet lab simulation. The result also affirms that of a previous study in the same location [7]. 
The participants $(n=8)$ were all male. Therefore, the findings of this investigation were not influenced by gender. The reason for this, apart from the small sample size, is that men continue to dominate the student population in most Nigerian medical schools especially subspecialties like neurosurgery which has the lowest number of female residents [11]. The literature revealed that the fall in women enrolment at the postgraduate level may be attributed to the stress of combining family responsibilities with their training [12], duration of the training, long work hours and high rate of patient acuity [11]. The study found the wet-lab training beneficial to the participants. They reported that it helped to improve their level of confidence; it restored their hope in the surgical training program and similarly upgraded their level of knowledge. All these were possible because the tutors/ trainers were adjudged competent, devoted to the training and patient with the trainees. In summary, the perception of the trainers and their teaching techniques by the residents was positive. Their self-perception was likewise positive, as the participants were hopeful that their skills would be refined. They noted that the training was worth their time and resources and that it would be beneficial for their future practices and careers.

Notwithstanding the positive evaluation, some of the participants, especially the ones in the more advanced phase of the medical training program, identified some challenges with the content of the wet-lab training. Others, on the other hand, identified such problems as high training fees, poor standard of equipment, poor time table, tight work schedule, the limited scope of the wet-lab training experience, short duration of the training, poor standard of specimen and problem of logistics. These challenges, however, are not peculiar to the study location as previous investigations have documented similar problems as reported by medical students in another center in Nigeria [12-14]. The participants, however, proffered solutions to some of these problems such as an increase in the length of the training and the number of training sessions. Other suggestions offered are sourcing for funds or sponsors and collaboration with other stakeholders outside the College of Medicine. The need to extend the training to residents in other Medical Schools was also mentioned, this is expected to promote the exchange of ideas amongst the medical trainees.

\section{Conclusion}

The result of this investigation affirms the importance of wet-lab training to medical education, quality of care and high performance in health-care service delivery. The study revealed that within many constraints, the trainers/educators have demonstrated unwavering commitment to impart requisite knowledge and practical skills on the residents. However, the shortcomings and suggestions for improving future training as proposed by the residents are worth addressing in order to maximize the gains of the hands-on experience. This will assist the educators to adequately meet the needs and expectations of their students and improve the quality of health-care delivery in our environment.

\section{Message to the reader}

Theoverallsubjectiveexperiences ofindividualsaffecttheir future participation, recommendation, and sustainability of a project. This study has utilized an approach that taps into the expertise of behavioral scientists to investigate the quality of the laboratory training activity with a view to understanding its perception by the group of participants. The major lesson from this study is that qualitative assessment is important for measuring participant's satisfaction and enhancing future endeavors in a similar activity. It is evident that a joint planning with potential participants rather than mere need assessment would have prevented the lapses noted in their comments. This study will help to improve accountability rather than just training evaluation by the group.

\section{References}

1. Al-Kabbaa AF, Ahmad HH, Saeed AA, Abdalla AM, Mustafa AM. Perception of the learning environment by students in a new medical school in Saudi Arabia: Areas of concern. J Taibah University Med Sci. 2012; 7: 69-75.

2. Taramsari MR, Badsar A, Seyednejad R, Maafib AM. Assessment of students' perceptions of educational environment in clinical wards of University hospitals at an Iranian Medical Sciences University. Social and Behavioral Sciences. 2012; 46: 715-720.

3. Bakhshialiabad H, Bakhshi $M$ and Hassanshahi G. Students perceptions of the academic learning environment in seven medical sciences courses based on DREEM. Adv Med Educ Pract. 2015; 6: 195-203.

PubMed: https://www.ncbi.nlm.nih.gov/pubmed/25848331

4. Soliman MM, Sattar K, Alnassar S, Alsaif F, Alswat K, et al. Medical students' perception of the learning environment at King Saud University Medical College, Saudi Arabia, using DREEM Inventory. Adv Med Educ Pract. 2017; 8: 221-227.

PubMed: https://www.ncbi.nlm.nih.gov/pubmed/28360540

5. Pai PG, Menezes V, Srikanth, Subramanian AM, Shenoy JP. Medical Students' Perception of Their Educational Environment. JCDR. 2014; 8: 103-107.

PubMed: https://www.ncbi.nlm.nih.gov/pmc/articles/PMC3939516/

6. Buhari MA, Nwannadi IA, Oghagbon EK, Bello JM. Students' perceptions of their learning environment at the College of Medicine, University of Ilorin, Southwest, Nigeria. West Afr J Med. 2014; 33: 141-145. PubMed: https://www.ncbi.nlm.nih.gov/pubmed/25236832

7. Odole AC, Oyewole 00, Ogunmola OT. Nigerian Physiotherapy Clinical Students' Perception of their Learning Environment Measured by the Dundee Ready Education Environment Measure Inventory. Int $\mathrm{J}$ Higher Edu. 2014; 3: 83-91.

8. Sideris M, Papalois A, Tsoulfas G, Majumder S, Toutouzas K Developing an International Combined Applied Surgical Science and Wet Lab Simulation Course as an Undergraduate Teaching Model. Biomed Res Int. 2015; 2015.

PubMed: https://www.ncbi.nlm.nih.gov/pubmed/26613083

9. Lynch P. Value of Wet Labs/Video: Dramatic changes over 20 years but more discussion at meetings is vital. Eurotimes. 2012; 17: 18-19. 
10. Pai PG, Menezes V, Srikanth, Subramanian AM, Shenoy JP. Medical Students' Perception of Their Educational Environment. JCDR. 2014; 8: 103-107.

PubMed: https://www.ncbi.nlm.nih.gov/pmc/articles/PMC3939516/

11. Renfrow JJ, Rodriguez A, Liu A, Pilitsis JG, Samadani U, et al. Positive Trends in Neurosurgery Enrollment and Attrition: Analysis of the 2000-2009 Female Neurosurgery Resident Cohort. J Neurosurg. 2016; 124: 834-839.

PubMed: https://www.ncbi.nlm.nih.gov/pubmed/26452119

12. Anyaehie UE, Anyaehie USB, Nwadinigwe CU, Emegoakor CD, Ogbu VO. Surgical Resident Doctor's Perspective of Their Training in the
Southeast Region of Nigeria. Ann Med Health Sci Res. 2012; 2:19-23. PubMed: https://www.ncbi.nlm.nih.gov/pmc/articles/PMC3507131

13. Adebamowo CA, Ezeome ER, Ajuwon AJ, Adekunle 00. Job stress associated with surgical training in Nigeria. Afr J Med Med Sci. 1998; 27: 233-237.

PubMed: https://www.ncbi.nlm.nih.gov/pubmed/10497656

14. Ojo EO, Chirdan OO, Ajape AA, Agbo S, Oguntola AS, et al. Postgraduate surgical training in Nigeria: The trainees' perspective. Niger Med J. 2014; 55: 342-347.

PubMed: https://www.ncbi.nlm.nih.gov/pubmed/25114372 